\title{
BONE BUTTRESS OPERATION FOR RECURRENT ANTERIOR SHOULDER DISLOCATION IN EPILEPSY
}

JAMES W. HUTCHINSON, LARS NEUMANN, W. ANGUS WALLACE

From Nottingham City Hospital, England

Patients suffering from generalised convulsions may dislocate their shoulders either anteriorly or posteriorly. Those with anterior dislocation are likely to have recurrent episodes because of secondary bony damage to the anterior rim of the glenoid and head of the humerus. In such patients there is high rate of failure of the standard soft-tissue stabilisation procedures. We have therefore devised a bone buttress operation in which autograft or allograft is secured to the deficient anterior glenoid and shaped to form an extension of its articular surface.

We report our experience in 14 patients with grandmal epilepsy and recurrent anterior dislocation of the shoulder. After the bone buttress operation there were no further dislocations and all patients were satisfied despite a small restriction in their range of movement. We believe this to be the operation of choice for patients with this difficult problem.

J Bone Joint Surg [Br] 1995;77-B:928-32.

Received 2 June 1995; Accepted 29 June 1995

J. W. Hutchinson, FRCS, Registrar

Department of Orthopaedics, Derbyshire Royal Infirmary, London Road, Derby DE1 2QY, UK.

L. Neumann, Consultant Orthopaedic Surgeon

Nottingham Shoulder and Elbow Unit, Nottingham City Hospital NHS Trust, Hucknall Road, Nottingham NG5 1PB, UK.

W. A. Wallace, FRCS Ed(Orth), Professor of Orthopaedic and Accident Surgery

Department of Orthopaedics, University Hospital, Queen's Medical Centre, Clifton Boulevard, Nottingham NG7 2UH, UK.

Correspondence should be sent to Professor W. A. Wallace.

(C)1995 British Editorial Society of Bone and Joint Surgery 0301-620X/95/61062 \$2.00
Patients suffering from generalised epileptic fits may sustain posterior dislocation of the shoulder (Taylor and Wright 1952; Arden 1956), but anterior dislocation is also seen. Jacobs, Patterson and Schultz (1970) reported a series of 40 dislocations of the shoulder in 37 patients who had seizures; 25 were anterior. Dislocations occur as a result of external trauma secondary to a fall during a fit or from powerful unco-ordinated muscle contractions around the shoulder. They are likely to recur because of the development of bony defects of the anterior rim of the glenoid and compression fractures of the humeral head caused by the very forceful dislocation (Hill and Sachs 1940). Standard soft-tissue operations for anterior instability, such as the Bankart (Bankart 1938) and Putti-Platt (Osmond-Clarke 1948) procedures, have a high rate of failure in these patients, probably because of the extensive bone defects. We have devised an operation to replace the bone lost from the anterior rim and to enlarge the surface of the glenoid anteriorly, thereby providing a wider stable arc of motion and preventing a large Hill-Sachs lesion from engaging on the deficient anterior rim, which leads to dislocation.

Mowery et al (1985) reported good results after applying a bone block to the posterior aspect of the glenoid in recurrent posterior dislocation. Recurrent anterior dislocation has been treated by different versions of the EdenHybinette procedure in which a small bone block is applied to the anterior rim of the glenoid either intra- or extraarticularly (Eden 1918; Hybinette 1932). Our bone buttress procedure differs in that it uses a large bone block to create a smooth anterior extension of the glenoid with much the same curvature.

\section{PATIENTS AND METHODS}

Between August 1988 and February 1993 we performed 17 bone buttress operations on 14 epileptic patients ( 3 bilateral). All procedures were undertaken by WAW or LN. One patient (bilateral) who emigrated was lost to follow-up. Of the remaining 13 patients ( 15 shoulders) the average age at operation was 29 years 1 month (19 years 5 months to 46 years; median 23 years 8 months). There were four women and nine men. The dominant arm was affected in nine patients. All patients had experienced generalised epileptic fits which had been poorly controlled with an average of 27 fits per year at the time of the first dislocation. Operation was delayed until control of the epilepsy was improved. 
Table I. Details of the number (percentage) and mechanism of the dislocations

\begin{tabular}{lcc}
\hline Mechanism & $\begin{array}{l}\text { First } \\
(\mathbf{n}=15)\end{array}$ & $\begin{array}{l}\text { Subsequent } \\
(\mathbf{n}=690)\end{array}$ \\
\hline Epileptic fit & $10(67)$ & $176(25)$ \\
$\begin{array}{l}\text { Traumatic, not } \\
\text { during fit }\end{array}$ & $3(20)$ & $20(3)$ \\
$\begin{array}{l}\text { Atraumatic, not } \\
\text { during fit }\end{array}$ & $2(13)$ & $494(72)$ \\
\hline
\end{tabular}

The average age at the first dislocation was 20 years 7 months (11 years to 41 years; median 18) and its mechanism is shown in Table I. It was not possible to ascertain whether the first dislocation occurring during a fit was caused by muscle contractions alone, or by the patient falling. Of the first dislocations, 12 were reduced in hospital emergency departments and 3 outside without analgesia or sedation. Before operation there had been an average of 46 dislocations per shoulder (4 to 120; mean 30) (Table I) and approximately $50 \%$ had been reduced in hospital emergency departments. Seven patients ( 8 shoulders) had previously had one or two unsuccessful stabilising procedures in various centres around the United Kingdom, which included three Bankart repairs, three Bristow procedures and six Putti-Platt operations.

Operative technique. The patient is placed in the deck- chair position. Through a deltopectoral approach, the coracoid process is predrilled and tapped for a small AO $4.0 \mathrm{~mm}$ half-threaded cancellous screw. Coracoid osteotomy at $1 \mathrm{~cm}$ from the tip of the process, allows it to be mobilised and reflected medially.

Subscapularis muscle is held with two double-loop stay sutures introduced as medially as possible under direct vision. This facilitates the subsequent repair and prevents accidental damage to the brachial plexus. Subscapularis is divided with cutting diathermy just medial to the musculotendinous junction, taking care not to damage the joint capsule. The muscle can then be separated from the capsule and retracted medially. The joint capsule is now exposed and a vertical arthrotomy performed along the anterior rim of the glenoid. The bony lesion is exposed and prepared by removing any fibrous tissue to form a bed of sound, partly decorticated bone.

Using either a tricortical iliac-crest graft $4 \mathrm{~cm}$ wide by $3 \mathrm{~cm}$ deep (Fig. 1a) or an allograft from a femoral head (Fig. 1b) the glenoid is then extended anteriorly by fixing the graft to the bony lesion with two large AO $4.5 \mathrm{~mm}$ cortical screws. When solidly fixed the graft is trimmed down to form a glenoid extension with the same curvature as the remainder. The glenoid surface thus created will be slightly wider than that of the anatomical glenoid in order to prevent the Hill-Sachs lesion from engaging the anterior rim (Fig. 2). Once trimmed the graft must be flush with the
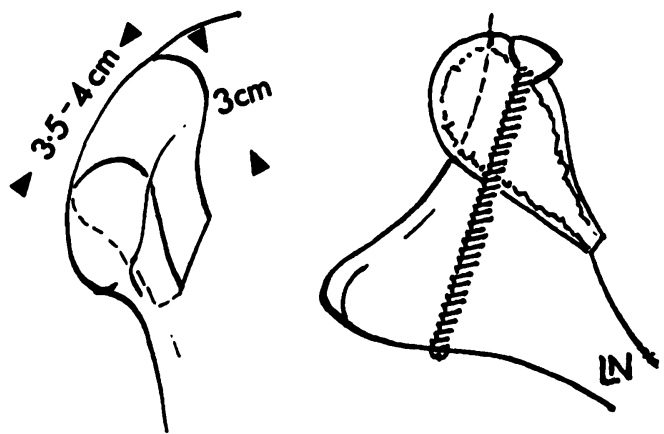

Fig. 1a
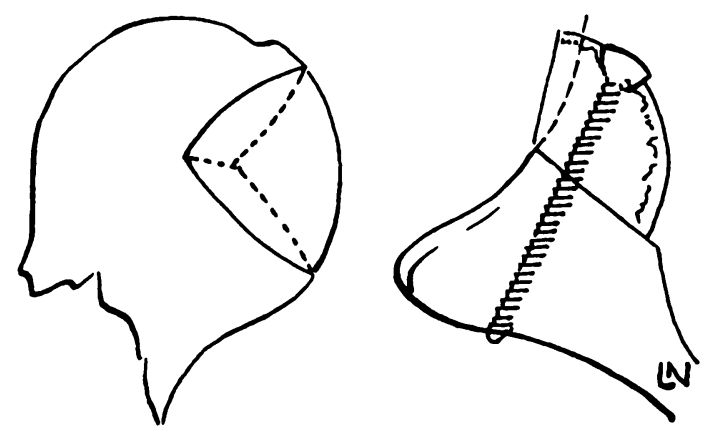

Fig. lb

Diagrams to show the origin and placement before trimming a tricortical iliac-crest autograft taken from behind the anterior superior iliac spine (a), and an allograft from a femoral head (b).
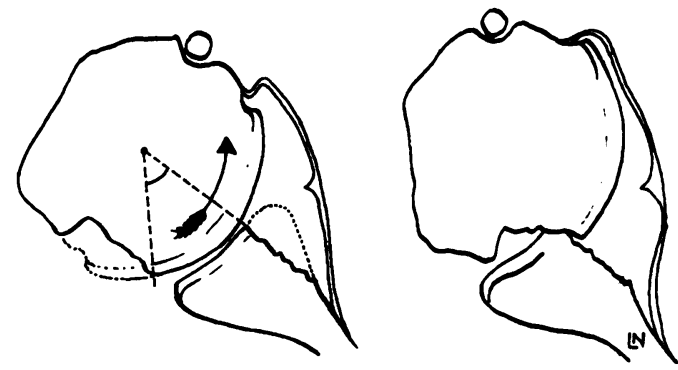

Fig. 2a
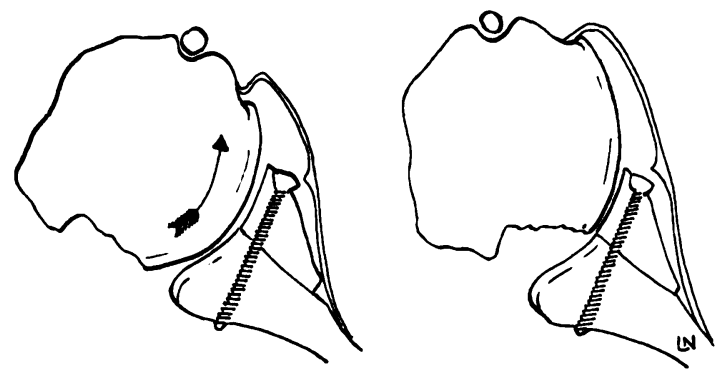

Fig. 2b

Figure $2 \mathrm{a}$ - In the presence of a Hill-Sachs lesion and bony Bankart lesion only a small range of external rotation is possible before the bony lesions engage and apprehension or dislocation occurs. Figure $2 \mathbf{b}-$ After bone grafting the glenoid extension allows for more external rotation. The bony extension is somewhat larger than the amount of bone lost from the glenoid rim. 


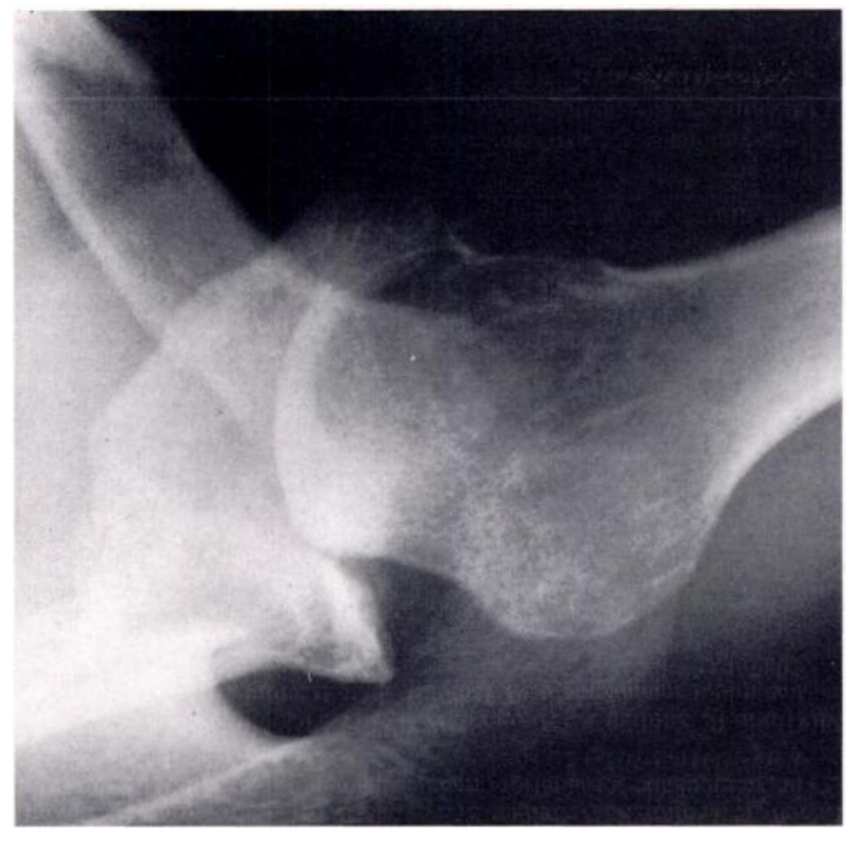

Fig. 3

Preoperative radiograph showing a large Hill-Sachs lesion almost engaging a bony Bankart lesion.

remaining glenoid. Figure 3 shows the preoperative situation with the Hill-Sachs lesion almost engaging the deficient glenoid rim. Figure 4 shows the incorporated graft and the extended glenoid. The capsule can then be held in position against the newly-created anterior glenoid rim by two No 2 Ethibond sutures tied around the screw heads.

In some cases the anterior capsule was not reattached, but no problems were encountered. The subscapularis is repaired without shortening and the tip of the coracoid is reduced and screwed into the previously prepared drill hole in its base.

After operation the arm is immobilised for four weeks in a broad arm sling with restricted external rotation. The sling is then discarded and the shoulder mobilised by the patient without formal physiotherapy, as the graft still needs protecting and will not withstand vigorous movements. If the range of motion is not improving satisfactorily at eight weeks, physiotherapy is started; by then the graft will be firmly seated and there may be some bony union.

All 13 patients (15 operated shoulders) were reviewed after an average follow-up of 32 months (8 to 61; median 27). Clinical examination by JWH included a Constant score assessment (Constant and Murley 1987) and measurement of power in external and internal rotation. A questionnaire was completed and routine and axial radiographs of the shoulder taken. The questionnaire included details of age, gender, epilepsy, profession, the effect of the dislocation on professional and social life, first and subsequent dislocations, details of previous surgery and patient satisfaction.

\section{RESULTS}

None of the 13 patients had any dislocations after the bone buttress operation, though eight continued to have generalised seizures.

Of the 11 patients who had a unilateral bone buttress operation eight had a 'normal' opposite shoulder which had never caused problems. The other three patients had a dislocating opposite side and were awaiting the bone buttress operation on it. The eight 'normal' shoulders and the three shoulders awaiting operation were assessed for comparison. Table II gives the average Constant scores for the three groups.

The Constant score is marked according to pain, activities of daily living (ADL), range of movement and power; Table III shows the breakdown of the scores in the three groups. Measurement of power in abduction is part of the Constant score; we also measured power in external and

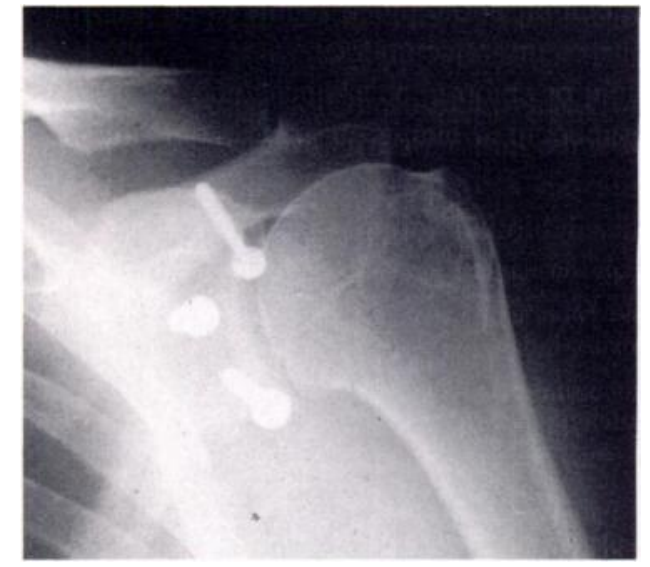

Fig. $4 a$

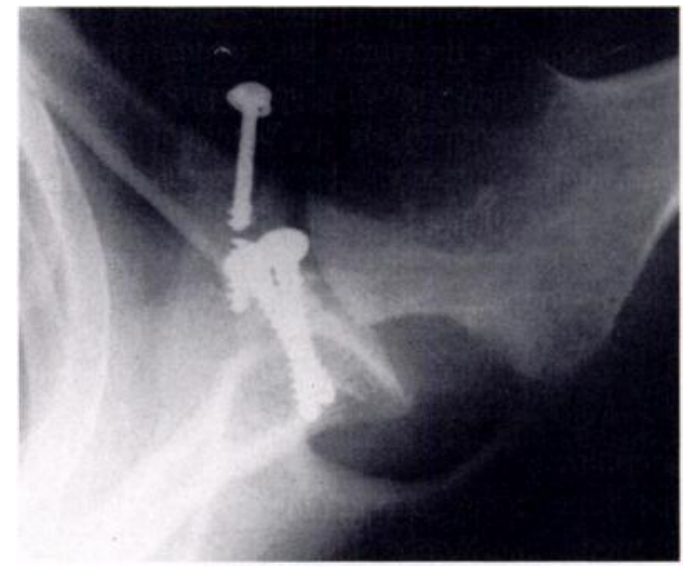

Fig. 4b

AP (a) and axial (b) radiographs at follow-up. In the AP view some degenerative changes are seen which are unchanged from before operation. 
Table II. Mean (range) Constant score for the three groups of shoulders

\begin{tabular}{ll}
\hline Shoulder group & Constant score \\
\hline Bone buttress $(n=15)$ & $91.3(71$ to 98$)$ \\
'Normal' $(n=8)$ & $99.2(94$ to 100$)$ \\
Awaiting bone buttress $(n=3)$ & $70.0(65$ to 79$)$ \\
\hline
\end{tabular}

no worse at follow-up.

Eight of the patients described themselves as more active since the operation and all expressed satisfaction with the outcome and would recommend the procedure to others in the same situation. The restriction in movement in comparison with a normal shoulder was not considered a problem

Table III. Breakdown of the Constant score and power in external and internal rotation in the three groups of shoulders

\begin{tabular}{|c|c|c|c|c|c|c|c|c|c|}
\hline \multirow[b]{3}{*}{ Maximum score } & \multicolumn{9}{|c|}{ Constant score } \\
\hline & \multirow[b]{2}{*}{$\begin{array}{l}\text { Pain } \\
\text { (15) }\end{array}$} & \multirow[b]{2}{*}{$\begin{array}{l}\text { ADL* } \\
(20)\end{array}$} & \multicolumn{4}{|c|}{ Range of movement $\dagger$} & \multicolumn{3}{|c|}{ Power } \\
\hline & & & $\begin{array}{l}\text { FL } \\
\text { (10) }\end{array}$ & $\begin{array}{l}\text { AB } \\
\text { (10) }\end{array}$ & $\begin{array}{l}\text { IR } \\
\text { (10) }\end{array}$ & $\begin{array}{l}\text { ER } \\
\text { (10) }\end{array}$ & $\begin{array}{l}\mathbf{A B} \\
\text { (25) }\end{array}$ & ER & IR \\
\hline $\begin{array}{l}\text { Bone buttress }(n=15) \\
\text { (mean score } 91.3 \text { ) }\end{array}$ & 14 & 19.9 & 9.3 & 8.7 & 7.6 & 8.7 & 23.1 & 18.4 & 20.1 \\
\hline $\begin{array}{l}\text { 'Normal' } \\
(n=8) \\
(\text { mean score } 99.2)\end{array}$ & 15 & 20 & 10 & 10 & 10 & 10 & 24.2 & 20.6 & 22.6 \\
\hline $\begin{array}{l}\text { Awaiting bone } \\
\text { buttress }(\mathrm{n}=3 \text { ) } \\
\text { (mean score 70.0) }\end{array}$ & 6.7 & 14 & 8.7 & 6.7 & 7.3 & 8.0 & 19.0 & 15.7 & 20.0 \\
\hline
\end{tabular}

* activities of daily living

$\dagger \mathrm{FL}=$ flexion; $\mathrm{AB}=$ abduction; $\mathrm{IR}=$ internal rotation; $\mathrm{ER}=$ external rotation

internal rotation with the elbow at the side. The 'normal' shoulders had a Constant score of nearly 100, as expected. The bone buttress shoulders scored well with a mean of 91.3. Points were lost in all sections of the scoring system but most in the range of movement section with external rotation most limited. The average external rotation with the elbow at the side and at $90^{\circ}$ of abduction in the bone buttress shoulders was $38^{\circ}$ (25 to 70 ) and $63^{\circ}$ (25 to 70 ) respectively. This compares with the corresponding average values in the 'normal' shoulders of $54^{\circ}$ and $89^{\circ}$. The best scores were obtained for pain and ADL.

The bone buttress shoulders scored much higher than the three shoulders awaiting operation and had a better range of movement; they were also stronger in external rotation and abduction. There was no demonstrable difference in outcome between those shoulders which had previous failed surgery and those for which it was the first procedure.

Nine patients received an allograft and six an autograft. We found no difference in the outcome between the two types of graft either clinically or radiologically but one patient in the autograft group had persistent pain at the donor site and one had annoying paraesthesia in the lateral thigh.

The preoperative radiographs had shown that all patients had major defects of the anterior rim of the glenoid reducing its size to two-thirds or less of normal; all patients had a Hill-Sachs lesion. Radiographs taken at review showed that all 15 grafts were in place with no sign of resorption, broken screws or screw migration. Some union seemed to have occurred in all patients. Before operation some of the joints had shown early degenerative changes but these were since they had a stable, non-dislocating, pain-free shoulder which they could trust.

\section{DISCUSSION}

Epilepsy is a stigmatising illness and current treatment aims to keep the patient out of hospital whenever possible. Our patients had a very high rate of shoulder dislocation before surgery and approximately $50 \%$ of these dislocations had been reduced in a hospital, representing considerable disability for the patient and a drain on hospital resources.

It is uncertain how many epileptic patients with recurrent dislocation are successfully managed by the standard softtissue stabilisation procedures, but in our series of 15 shoulders, all referred from elsewhere, eight had had 12 previous unsuccessful operations. This failure rate is possibly due to the unco-ordinated muscle forces which can be exerted during a grand-mal seizure. Shoulder stability is unlikely to be regained without addressing the important problem of bone deficiency.

To date, our operation has been successful in abolishing further dislocation at the cost of a limited restriction in range of movement, although after operation these shoulders had a greater range of movement than those awaiting surgery. The presence of both a Hill-Sachs lesion and a defect of the anterior glenoid gives a very small arc of stable motion, and the two bony lesions may engage early in external rotation, giving a positive apprehension test.

There was no detectable difference in outcome or radiological appearance between the use of autograft or allograft. Because of some problems with the donor site we 
favour the use of allograft when this is available and acceptable to the patient.

Our longest follow-up was for just over five years; radiological incorporation had occurred with no resorption and there were no additional degenerative changes. After the Eden-Hybinette procedure there is a high incidence of late degenerative joint disease (Hindmarsh and Lindberg 1967; Paavolainen et al 1984), and our follow-up is too short to exclude this complication. The aim of our operation is to restore the severe bone loss by providing a flush extension of

\section{REFERENCES}

Arden GP. Posterior dislocation of both shoulders: report of a case. J Bone Joint Surg [Br] 1956;38-B:558-63.

Bankart ASB. Pathology and treatment of recurrent dislocation of shoulder-joint. Br J Surg 1938;26:23-9.

Constant CR, Murley AHG. A clinical method of functional assessment of the shoulder. Clin Orthop 1987:214:160-4.

Eden R. Zur operation der habituellen Schulterluxation unter Mitteilung eines neuen Verfahrens bei Abriss am inneren Phannenrande. Dtsch Z Chir 1918;144:269-80.

Hill HA, Sachs MD. Grooved defect of humeral head: a frequently unrecognized complication of dislocations of shoulder joint. Radiology 1940;35:690-700.

Hindmarsh J, Lindberg A. Eden-Hybbinette's operation for recurrent dislocation of the humero-scapular joint. Acta Orthop Scand 1967;38:459-78. the glenoid surface which does not impinge on the humeral head. It differs from that used by Mowery et al (1985) which creates a buffer stop. In the Eden-Hybinette procedure the graft is much smaller and is not intended to extend the normal curvature of the glenoid. Degenerative changes may be due to multiple subluxation or dislocations; the influence of the repair operation performed remains uncertain.

No benefits in any form have been received or will be received from a commercial party related directly or indirectly to the subject of this article.

Hybinette S. De la transplantation d'un fragment osseux pour remédier aux luxations récidivantes de l'épaule: constatations et résultats opératoires. Acta Chir Scand 1932;71:411.

Jacobs BW, Patterson RL Jr, Schultz TJ. Shoulder dislocations associated with seizure disorders. J Bone Joint Surg [Am] 1970;52-A:824.

Mowery CA, Garfin SR, Booth RE, Rothman RH. Recurrent posterior dislocation of the shoulder: treatment using a bone block. J Bone Joint Surg [Am] 1985;67-A:777-81.

Osmond-Clarke H. Habitual dislocation of the shoulder: the Putti-Platt operation. J Bone Joint Surg [Br] 1948;30-B:19-25.

Paavolainen P, Björkenheim JM, Ahovuo J, Slätis P. Recurrent anterior dislocation of the shoulder: results of the Eden-Hybbinette and PuttiPlatt operations. Acta Orthop Scand 1984;55:556-60.

Taylor RG, Wright PR. Posterior dislocation of the shoulder. J Bone Joint Surg [Br] 1952;34-B:624-9. 